\title{
Lost in translation in the middle of nowhere
}

\author{
Tatjana MARJANOVIŠ \\ University of Banja Luka \\ Bosnia and Herzegovina
}

\begin{abstract}
Essentially a personal account of how translation is taught and assessed in the English department at the University of Banja Luka, this paper has been written in a very down-to-earth tone aiming to explain a broader social and educational context which determines the way translation is perceived in and outside the classroom. Going beyond a critical overview of how the department's translation class is managed, the paper ends with practical suggestions as to how translation teaching and assessment could be improved despite a number of institutional limitations surrounding it.
\end{abstract}

Key words: translation, educational and social context, teaching and assessment.

\begin{abstract}
Il presente lavoro, in sostanza un resoconto sullo svolgimento del processo di insegnamento e di valutazione della traduzione nel dipartimento di Inglese dell'Università di Banja Luka, è stato elaborato tenendo presente un contesto sociale ed educativo più esteso, responsabile, tra l'altro del modo in cui venga percepita la traduzione al di fuori del mondo universitario. Andando oltre l'analisi critica delle modalità di funzionamento della traduzione come disciplina nel nostro dipartimento, questo lavoro si conclude con dei suggerimenti di carattere pratico su come migliorare il processo di insegnamento e di valutazione della traduzione, a discapito di non poche limitazioni istituzionali.
\end{abstract}

Parole-chiave: traduzione, contesto educativo e sociale, processo di insegnamento e di valutazione

\section{The social context of translating in Banja Luka, Bosnia and Herzegovina}

Living in a country that is nowhere close to becoming a member of the European Union means more than two things, but these may be the most relevant ones from the perspective of translation business: a shrinking market and virtually no need for quality control.

Even though there is no official information about the number of our students doing translation jobs, every now and then I hear of soand-so working in a governmental department or a bank, or doing conference interpreting in the areas of politics and education, or being 
commissioned for a translation project by individuals and institutions alike. In private encounters with some of those who can consider themselves lucky to have a job, I listen patiently and sympathize with them as they complain about being made to translate too much for little money, as well as about their unprofessional and disrespectful treatment by an employer who more often than not fails to acknowledge the skill and knowledge required of a good translator.

Unfortunately, I have to say that I am not surprised to learn of such experiences, being all too aware that a huge majority of these movers and shakers in need of translation services do not speak a foreign language to begin with. Some of them do, but as a rule it is not English. The trend is a social and political legacy of a long reign of Russian in the context of formal education, which resulted in a relatively recent introduction of English to primary and secondary school students.

The founding of an English department in Banja Luka, Bosnia and Herzegovina, in 1994 could be seen as another indication of changing priorities in education and the country's sociopolitical and economic life. I recollect such a shortage of English speakers in the post-war Bosnia that a mass testing of prospective 'language assistants' administered by the UN forces virtually left the English department empty of students! This exposure to English and the opportunity to work alongside native speakers (not that the entire mission was nativespeaking, of course) may have been a silver lining in the unthinkable horror of the recent war in Bosnia.

Truth be told, most of the students hired were uniform-clad field interpreters working in rather difficult conditions, often for days and weeks away from home, which was a far more challenging aspect of the job than the relatively simple translation tasks they had to perform for the peace-keeping forces. I knew most of them before and after the job, and I can say that there usually was no miraculous transformation from a barely functional speaker of English to a fully functional one. For some of them there was another gain to be made, though: they married their English-speaking superiors or colleagues and forever left Bosnia to live their own happily-ever-after stories.

Those who were assessed to have a very good to exceptional command of the language at the time of testing were assigned to one of the diplomatic missions and their various offices set up throughout the country, such as the Office of the High Representative (OHR) or the Organization for Security and Co-operation in Europe (OSCE). I myself worked for both of these, and some fifteen years later I can say that, although it did not get me a husband, this experience not only improved my overall language proficiency and helped raise my cultural awareness, but also offered me the invaluable on-the-job translation training, the only form of training I was to get in my undergraduate education. 
Although my superiors were not language experts, they were highly educated native speakers of standard British and American English. Many were holders of a master's degree or an equivalent in their field of expertise, and they acted as my proofreaders and teachers: my job was to translate media texts from Serbian to English on a daily basis, and then we would go through the texts together. Much as their informal linguistic background and pedagogical skills prevented a truly technical interpretation of my work expressed in all the right metalanguage, their intuitive comments were very well placed and taught me a great deal about the fine line between grammaticality and acceptability, matters of frequency, and the overarching importance of context.

A couple of years later I resumed my studies, graduated and accepted a teaching assistant position at the University of Banja Luka. I believe this experience, coupled with my general language proficiency and a competitive grade point average, was critical in appointing me to teach the senior year L2 translation class. It is common in this part of the world to have teaching assistants, and almost never PhDs and professors, teach what is universally referred to as the language skills, translation into L1 and L2 included. This practice seems somewhat counterintuitive: why deny teachers the possibility to pass on the knowledge that has hopefully amassed as they progress from one academic stage to another? As expected, the explanation for this is technical rather than philosophical: both L1 and L2 translation are part of the package labelled in the syllabus as Contemporary English 1-8, distributed and taught in each of the eight semesters of English studies at the University of Banja Luka. By way of illustration, the day I earned my doctoral degree, I was no longer considered eligible to teach translation.

Yet, I have to admit that I was slightly relieved that this was the case, the relief stemming from persistent feelings of inadequacy and a constant reminder that I had no formal translation (teacher) training and very little institutional network support. For instance, the presence of a native speaker with whom I could share the L2 translation class was not an option, and the much-needed coordination with other Contemporary English instructors was not a formal requirement, which basically meant that there were few colleagues willing to cooperate. Admittedly, both the teaching assistants and their senior colleagues have been struggling under a perilously heavy workload ever since the introduction and implementation of the Bologna process, and have effectively been turned into administrative workers filling out forms and churning out spreadsheets under tremendous time constraints.

The translation market, however diminished with the internationals gradually leaving the country, is motley and gravely under-researched, which makes it impossible to determine the exact needs of the students taking translation classes. Secondly, to provide for all the diverse leanings on the translation market that seem likely to 
emerge will be even more difficult, especially given the fact that translation is not taught as a course per se in Banja Luka's English department or within any other institution in this part of Bosnia and Herzegovina.

As for translation quality control, it is not institutional but basically client-driven and disseminated largely by word of mouth. There are very few formal selection criteria, even for authorized court interpreters: to my knowledge, there is an interview following a candidate's application, which is contingent upon one's proof of holding a bachelor's degree in English, and most applicants are ultimately granted the 'stamp' (i.e. authorized to do official translations) - it is just that some are made to wait a little longer than others. On the other hand, the fact that Banja Luka's English department is a young institution which has yet to prove its credibility on the market, the more challenging a translation job is considered to be (e.g. conference interpreting), the more likely it is to land in the hands of a graduate from a university with a longer history in the Serbian-speaking region, such as the University of Belgrade.

\section{The educational context of teaching translation in the English department of the University of Banja Luka}

Translation is somewhat of a buzzword at our departmental meetings and amongst our students: it comes up so often that one would be led into thinking that it is actually taught as a separate course. In reality, ours is one of those philology (or modern languages) departments that teach translation in order to improve their students' linguistic proficiency, but many of our students will say that it is their worst nightmare. To be more precise, the nightmare is regularly associated with L2 translation, and it is not so much the activity itself as it is the assessment that keeps them awake at night.

The English language and literature undergraduate degree programme at the University of Banja Luka is centred round Contemporary English courses taught in each of the eight semesters and consisting of general English (spoken and written), composition, and translation into Serbian and English. During and/or at the end of each semester the students are assessed and assigned numerical grades in each of the components, and a grade in a Contemporary English course as a whole is derived from all the grades in the component courses, all of which have to be passes if the final grade is to be a pass too. In other words, if a student fails only one of the course component examinations (i.e. dictation, essay, L1 translation, L2 translation, and spoken English), the final grade awarded is not a pass. And, of course, what the students generally feel the least comfortable with, or the most difficult to deal with, is the L2 translation.

There seems to be a general consensus or feeling that translating into L2 presents quite the challenge (Schjoldager 2004, 
138). For example, the results of a study designed by Kiraly $(1995,109)$ to compare the quality of L2 translation testing both professional translators and novices were rather discouraging as neither group produced particularly good translations. Indeed, what can be loosely termed as Western ideology takes a generally negative stance on L2 translation, but is generally opposed to East-European practices (Gile 2005, 141), mostly for practical reasons. Pokorn's (2005) is one of those voices questioning the traditional axiom that non-native speakers of a language are incapable of producing high-quality translations into that language. The issue whether L2 translation is (im)possible is not of crucial importance in this discussion since it will not absolve the students of English at the University of Banja Luka from taking the course and undergoing testing.

But the question of what translation basically means in the context of this department's teaching and assessment is one worth parsing. If translation is a sociocultural communicative act which goes beyond the issue of lexical and structural equivalence (e.g. Baker, 1992), then, in all honesty, it is not taught here. However, let us not completely dismiss the idea of philological translation, which is a purposeful activity if done knowingly and aimed strategically (Schäffner 2004, 122). Although restricted in scope and not strictly rooted in any one theory of translation, it is an attempt at raising the students' awareness of how complex and multifaceted translation as a process normally is. Given that the department predominantly provides training for future teachers, the general aims of teaching, translation included, are both linguistic and pedagogical. But because we strive, sometimes too optimistically, to have teachers of English who actually speak and know the language, and because we expect some of our students to be doing translation jobs, we professors have to make the most of our translation class.

This is often easier said than done, and even though the reasons are manifold, poor selection criteria seem to be a particularly salient factor. The entrance exam is more than a formality nowadays, but the central management of the University has been overly lenient and expanded the official acceptance lists too readily in the past, leaving the teachers to struggle with scores of students who are well below the minimum requirement criteria. The trend of studying 'for leisure and pleasure' is generally on the rise, and there is growing pressure on us teachers to reduce the percentage of fails to the point of rewarding sheer ignorance.

This portrayal of a broader educational context in which translation has to be taught brings home the precariousness of the entire undertaking. Even to call it translation is probably amiss, but the apparent misnomer persists for want of another, more precise but equally succinct, term. It is crucial, however, that we remain fully aware of what and who it is used for, and that it has been redefined. 


\section{On what we do, what we do not do, and what we could do in our 'translation' class}

One of the aims of translation in our department is raising the students' linguistic awareness, which is why we tend to focus on the structural aspect of texts. By encouraging the students to work on their grammar of orientation (Willis 2003, 34) through translation, we try to make the form-meaning associations the centre of attention.

The rationale is an overall poor performance in the linguistic courses taught alongside Contemporary English (e.g. Morphosyntax and Syntax), and the students' naive understanding that language proficiency is best attained through the knowledge of individual words and idiomatic expressions. What we try to bring home is an understanding that structures are just as meaningful as words and idioms are, and that some forms have acquired meanings to serve specific communicative purposes, e.g. to provide contrast or emphasize the speaker's point of view (Baker 1992, 134).

To say that the students find the idea of a functional grammar (Halliday 1985) puzzling is an understatement: however hard we try to select texts for translation that incorporate the features taught in a parallel linguistic course, the students mostly fail to connect the dots and put to practice the knowledge imparted to them in a module with a different name. Sadly, to a vast majority of them these worlds just do not mix.

Still, we go to great lengths not to reduce our translation class to a 'read and translate' model, nor to wrongly use it as a venue for the grammar-translation method. It is true that the students are usually given their texts beforehand and that the focus is largely structural, but we strive to keep the discussion alive and encourage participation by making the students pay attention to all the strata of meaning: lexical, grammatical, and textual (Baker 1992).

Speaking from experience, such classroom plans often prove too ambitious and are easily thwarted by an excess of binary errors of a basic kind (Preložníková and Toft 2004, 87) and insufficient L1 knowledge. Needless to say, such mishaps diminish even further any remaining hopes of a successful L2 translation class. When the students make too many cardinal mistakes, such as consistently putting an indefinite article before a plural noun or repeatedly failing to indicate agreement between a third person singular subject and its present simple predicate, it is somewhat pointless to bring up the issue of textual equivalence and contrastive rhetoric (or is it not?).

Nevertheless, we always aim to keep translation in tune with the other modules taught in the same year. For the first-year students, among other things, it is the tense paradigm and the system of determination (Thomson and Martinet 1986); the year-two students deal with the complex noun phrase in English (Quirk and Greenbaum 1973); the third year grapples with some of the central systemic- 
functional notions, notably thematic and information structures and markedness (Downing and Locke 2002); and the final year is envisaged as a synthesis of the diverse but compact linguistic knowledge taught in the previous semesters.

It is hard to predict whether the students can see a pattern in having their translation texts match what is taught in the other courses in the syllabus, so they are occasionally reminded of this practice and all its benefits very explicitly, i.e. by literally showing it to them. Explicitness does not always lead to recognition and understanding, however, which is obvious in the way most of our students label the sentences numerically in the text they are translating, i.e. 1, 2, 3, etc. This is an indication that they persist in operating at sentence level, and that in-class discussions about cohesive devices, thematic progression, or information focus still have not made their way into the students' interlanguage. In all honesty, I have seen translation exam texts labelled the same way by the instructors/assessors themselves, but I want to believe that this is done for practical reasons, i.e. being just a convenient way to keep track of the score, rather than as a result of a total disregard for text as a unit of translation.

The painful issue of assessment may prompt us to consider not only assessing the students' translations differently, but also introducing novel ways in teaching translation both in and out of the classroom. Kiraly $(1995,110)$ reasonably suggests modifying 'the expected outcomes of the course' if and when the bar is obviously raised too high for the students. Such circumstances call for a very careful selection of both practice and exam texts in order to control the level of difficulty. For example, the students' examination anxiety can be alleviated by strategically avoiding syntactic complexities assessed to be beyond their grasp, archaic and low-frequency vocabulary, as well as idiosyncratic genres with features not commonly found in general texts. It is also recommendable, in my opinion, to make practice texts more demanding than the ones used for actual testing.

If examination results remain consistently at the lower end of the instructor's assessment scale despite all the modifications made, it may be worth supplementing the traditional translation exam format with tasks and assignments that do not necessarily come in the form of a written text. It has never been the policy of our department to assign grades for take-home assignments for fear of the students having somebody else do the work for them. Even though the fear is certainly justified, potentially abusive practices can be controlled by a follow-up conversation in which the students are asked to explain or defend some of their choices to the examiner. The students could be asked to rephrase a structure as instructed (e.g. build a complex noun phrase, form a cleft sentence, apply inversion, etc.), supply an appropriate synonym and collocation, or make changes to some of the discursive features observed in their translations (e.g. the given-new tendency, thematic progression, syntactic strategies in assigning focus, etc.). 
There is no guarantee that this would actually improve the students' chances of passing the exam or receiving a better mark, but it certainly is a way to regain some control of translation as a process instead of focusing solely on the product. Naturally, this shift of focus would have to run parallel with developing new learning skills and making the students responsible for their learning. They are likely to need assistance in the process of becoming more autonomous learners, which cannot commence without them discarding the deeply rooted habit of passive studying in and out of the classroom and getting equipped with the right tools to initiate the change.

No reference tool or suggestion is too basic or insignificant to start with. Take dictionaries, for example. It should not come as a surprise that the wealth of information dictionaries offer to their users is largely overlooked by too many students. These invaluable learning aids are underused to the point that looking up a word becomes the only reason to take a dictionary off a shelf. Such a grave misconception needs to be rectified without further delay, and there are exercises galore to help steer the students in the right direction. Showing students how to use the internet to do both simple and serious research can be fun and enlightening in more than one way. It had never occurred to me that I would have to remind my students that a simple Google search might actually do the trick, but then I asked and received yet another surprising answer. Working with large corpora (e.g. COCA) surely requires more skill and time, but now that some of them are available on-line and free of charge, learning to manipulate them and run interesting probes may just be worth the effort if the gain is an autonomous advanced learner making unexpected linguistic discoveries (Bernardini 2004).

Some of my students also have insufficient command of L1, which is why the power of reading must never be underestimated (Nord 2005, 212). Reading comes before translating, which is why both extensive and analytical reading in both $\mathrm{L} 1$ and L2 does the essential preparatory work and paves the way for translation. Important lessons in translation can be learned by having students merely compare a text and its translation, i.e. analyze somebody else's (non)-authorised translation. (I would opt for this activity when the actual translating became too strenuous, the students were clearly growing jaded and disheartened, and there seemed to be nothing but a dead end ahead of us.)

As much as possible I tried to refrain from the common practice of using canonized texts with translations that were looked upon as perfect, i.e. carved in stone and impervious to change. The almost divine status of such translations only aggravated the stress of being involved in an already stressful activity, lowered the students' selfesteem and inhibited their willingness to participate and use their critical faculties. In other words, they were too cognizant of the contrast between their position and the task at hand. 
Although our translation class is dominated by literary texts, these are occasionally supplemented with texts belonging to other genres, e.g. media texts, provided their format and register fall within the scope of general discourse and language. The choice not to stray far from the realms of neutral form and content has diminished the presence of texts with a strong technical bias, e.g. manuals, scientific publications, legal documents, and so forth. One of the reasons is that each of them is thought to be too idiosyncratic when analysed on its own. On the other hand, as the categorization of these non-literary texts is much too diverse and heterogeneous, an unselective approach becomes immediately unrealistic.

This is not only because some ten plus weekly teaching blocks of an hour and a half are hardly enough time for such an ambitious undertaking, but also because we are still not in possession of any verifiable institutional information what kind of translating jobs our students actually do when they do not (wish to) pursue a career in teaching or another line of work. Also, it is clearly stated in all our graduating students' certificates that the academic title officially conferred upon them is that of a teacher of the English language and literature. In such circumstances specialisation in the translation class (Kiraly 1995, 17) becomes increasingly difficult both to attain and justify.

This sadly means that the students will have to learn the ropes alone when faced with the demands of a technically oriented translation task in real life. Our only hope is that if the students become well acquainted with the general principles of the process, if they have the know-how enabling them to choose the right approach, they will manage to do their own research into a specific genre and isolate the salient features that make it different from other text types in both L1 and L2. I do realize that such expectations are very utopian, but if only a handful of students rise to the challenge, then even this far-fetched agenda appears to be more purposeful than spending the time we do not have trying to prepare the students for the jobs we do not know they will be doing.

In this case the focus on literary texts persists not necessarily for aesthetic reasons, but for their enriching yet balanced quality: literary texts encompass a wide scope of human experience and enter its many substrata when they 'reflect and interpret individual and social life, whether real or imaginary' (Knapp and Watkins 2005, 29). By relying on literary texts we do not necessarily have to sacrifice the general neutrality of form and expression if the aim is not to delve into the specific conventions of any one text type. Yet, the linguistic richness of literary texts, both lexical and structural, is such that it enables us teachers to address any points we wish to raise with our students, especially major difficulties and pitfalls lurking between the lines. Needless to say, literary texts lend themselves to an in-depth analysis of 
discursive features and text organization, both of which may easily undergo significant changes in the process of translation.

\section{Closing remarks}

Despite the fact that the University of Banja Luka does not specifically aim to train professional translators/interpreters, some of its students do seek and receive employment in this line of work. Much as teaching translation for philological purposes cannot be equated with specifically designed translation courses offering training to future professionals in the field, receiving some education from institutionally untrained (and often self-taught) translation teachers is still a better option than receiving no education at all. Even though the little education received cannot miraculously turn our students into trained translators, if that is all we can do with the resources that we have at our disposal at this point in time, then so be it.

There are, however, some aspects of our work that need improvement, and before succumbing to the temptation to write the idea off on account of it being impossible to materialize and point the finger of blame at the myopic manner in which the educational system is managed, I would like to remind myself more than anybody else that small changes are possible, especially those originating in and depending on me rather than the system. While waiting for the importance of coordination, institutional support and selection criteria to sink in with our decision-makers, I can look for a way to adjust to the less-than-perfect conditions of teaching translation in this part of the world without losing self-respect or my touch with reality.

Modifying my expectations may be the first logical step to make, and making the students accountable for their own learning may be the next. From there will follow decisions of a more practical kind, such as breaking out of the established routines in translation teaching and assessment not only by selectively introducing some of the many procedures proposed by trained translation teachers (e.g. Davies 2004), but also by wisely identifying the ones that truly work in the classroom.

\section{References}

Baker, Mona. In Other Words: A coursebook on translation. London: Routledge, 1992.

Bernardini, Silvia. 'Corpus-aided language pedagogy for translator education', in Kirsten Malmkjær (ed.), Translation in Undergraduate Degree Programmes. Amsterdam: John Benjamins Publishing Company, 2004: 97112.

Davies, Maria González. Multiple Voices in the Translation Classroom: Activities, tasks and projects. Amsterdam: John Benjamins Publishing Company, 2004.

Downing, Angela and Locke, Philip. A University Course in English Grammar. London: Routledge, 2002. 
Gile, Daniel. 'Teaching conference interpreting: A contribution', in Martha Tennent (ed.), Training for the New Millennium: Pedagogies for translation and interpreting. Amsterdam: John Benjamins Publishing Company, 2005: 127-152.

Halliday, Michael A. K. An Introduction to Functional Grammar. London: Edward Arnold, 1985.

Kiraly, Donald C. Pathways to Translation: Pedagogy and process. Kent, Ohio: Kent State University Press, 1995.

Knapp, Peter and Watkins, Megan. Genre, Text, Grammar: Technologies for teaching and assessing writing. Sydney: University of New South Wales Press, 2005.

Malmkjær, Kirsten (ed.). Translation in Undergraduate Degree Programmes. Amsterdam: John Benjamins Publishing Company, 2004.

Nord, Christiane.'Training functional translators', in Martha Tennent (ed.), Training for the New Millennium: Pedagogies for translation and interpreting. Amsterdam: John Benjamins Publishing Company, 2005: 209224.

Pokorn, Nike K. Challenging the Traditional Axioms: Translation into a nonmother tongue. Amsterdam: John Benjamins Publishing Company, 2005.

Preložníková, Soňa and Toft, Conrad. 'The role of translation studies within the framework of linguistic and literary studies', in Kirsten Malmkjær (ed.), Translation in Undergraduate Degree Programmes. Amsterdam: John Benjamins Publishing Company, 2004: 83-96.

Quirk, Randolph and Greenbaum, Sidney. A University Grammar of English. London, 1973: Longman.

Schäffner, Christina. 'Developing professional translation competence without a notion of translation', in Kirsten Malmkjær (ed.), Translation in Undergraduate Degree Programmes. Amsterdam: John Benjamins Publishing Company, 2004: 113-126.

Schjoldager, Anne. 'Are L2 learners more prone to err when they translate?', in Kirsten Malmkjær (ed.), Translation in Undergraduate Degree Programmes. Amsterdam: John Benjamins Publishing Company, 2004: 127-150.

Tennent, Martha (ed.). Training for the New Millennium: Pedagogies for translation and interpreting. Amsterdam: John Benjamins Publishing Company, 2005.

Thomson, Audrey J. and Martinet, Agnes V. A Practical English Grammar. Oxford: Oxford University Press, 1986.

Willis, Dave. Rules, Patterns and Words: Grammar and lexis in English language teaching. Cambridge: Cambridge University Press, 2003. 